\title{
Analysis of the 2nd symposium "Anomalies of fatty acids, ageing and degenerating pathologies"
}

\author{
Philippe GUESNET ${ }^{a *}$, Jean-Marc ALESSANDRI ${ }^{\mathrm{a}}$, Sylvie VANCASSEL ${ }^{\mathrm{a}}$, \\ Nicolas ZAMARIA ${ }^{b}$ \\ a Neurobiology of Lipids, The Nutrition \& Food Safety Laboratory, Institut National de la Recherche \\ Agronomique (INRA), CRJ, 78352 Jouy-en-Josas Cedex, France \\ b Laboratoire de Biologie Médicale, 49 avenue de Versailles, 75016 Paris, France
}

\begin{abstract}
The second symposium on anomalies of fatty acids, ageing and degenerating pathologies for the French-speaking community was held during January 2002 in Paris (France) and reunited more than 200 participants, including a majority of medical practitioners. It was organised around 8 conferences treating the following subjects: a general presentation of the metabolism of fatty acids and their biological functions (in particular polyunsaturated fatty acids or PUFA), the exploration of PUFA in man during situations of nutritional and pathological disequilibrium, and the importance of PUFA in the aetiology and prevention of pathophysiologies such as cardiovascular, autoimmune and inflammatory diseases, diabetes and obesity, cancer and certain neuropsychiatric affections such as depression. Indeed, even though edible fatty acids present a common energetic function, by $\beta$-oxidation, and a structural function, as a constituent of membrane lipids, some of them have a more specific role as an essential nutrient. These are essential fatty acids including the two families of polyunsaturated fatty acids ( $n-6$ and n-3 PUFA). Their metabolism leads to the synthesis of derivatives found in cellular membranes (structural role) and oxygenated molecules, the eicosanoids, whose main action is of the same type as that of hormones. These derivatives and oxygenated molecules also regulate different metabolic pathways by modulating the expression of target genes via activation of specific transcription factors. Due to their quality and their quantity in food, the PUFA may interfere with the incidence of a large number of pathologies whose causes are varied (cardiovascular and inflammatory diseases, cancers, neuropathologies, ...). The particular interest in nutrition of PUFA of the $\mathrm{n}-3$ series (or $\omega 3$ ) and in particular of long-chain derivatives mainly found in high quantity in fish oils (eicosapentaenoic acid and docosahexaenoic acid) is now widely confirmed for cardiovascular and inflammatory physiology and formed the subject of increasing investigations for prevention of certain pathologies of the central nervous system. In this paper, we are first going to recall the generalities of metabolism and functional properties of PUFA. Secondly, we will list the pathologies whose frequency and symptoms are susceptible to be corrected by the dietary intake of PUFA, notably by reaching the nutritional equilibrium between the family of linoleic acid (n-6 or $\omega 6)$ and that of $\alpha$-linolenic acid (n-3 or $\omega 3)$.
\end{abstract}

polyunsaturated fatty acids (PUFA) / docosahexaenoic acid (DHA) / eicosapentaenoic acid (EPA) / metabolism / cardiovascular diseases / autoimmune and inflammatory diseases / neuropathologies / cancer / diabetes / obesity

\footnotetext{
* Corresponding author: guesnet@jouy.inra.fr
} 


\section{THE FATTY ACIDS FAMILIES - THEIR STRUCTURE, NOMENCLATURE AND DIVERSE BIOLOGICAL EFFECTS}

Fatty acids are grouped in distinct families according to the number of ethylenic bonds (unsaturations) that they contain: saturated fatty acids or SFA (no double bond), monounsaturated or MUFA (only one double bond) or polyunsaturated or PUFA (at least two double bonds). Two families of PUFA can be distinguished by the position of the first double bond situated near the methyl extremity: the family of linoleic acid (n-6 or $\omega 6$, 6th position when counting from the methyl end) and that of $\alpha$-linolenic acid ( $\mathrm{n}-3$ or $\omega 3,3$ rd position when counting from the methyl end) [1]. Physiologists characterise fatty acids using a nomenclature in which successively figures the number of carbon atoms, the number of double bonds and the position of the first double bond (counted from the methyl end) (Tab. I).

The SFA and MUFA are not essential for man because they are synthesised de novo from glucose and acetyl-CoA in different tissues (liver, brain, adipose tissue). However, the metabolic precursors of the two families of PUFA, that is linoleic acid $(18: 2 n-6)$ for the $n-6$ family and $\alpha$-linolenic acid (18:3n-3) for the n-3 family, are essential fatty acids. These two fatty acids, once absorbed, lead to the specific synthesis of long-chain active derivatives formed by a desaturation-elongation successive process with double bonds and additional carbon atoms being added near the carboxyl extremity (activated with CoA) (Fig. 1). The main long-chain PUFA derivatives formed by animals are dihomo- $\gamma$-linolenic acid (20:3n-6 or DGLA) and arachidonic acid (20:4n-6 or AA) for the n-6 family and eicosapentaenoic acid (20:5n-3 or EPA) and docosahexaenoic acid (22:6n-3 or DHA) for the n-3 family (Fig. 1 and Tab. I).

SFA and MUFA are major constituents of stored triglycerides and of the phospho- lipids of lipoproteins and cellular membranes. They are implicated in the production and storage of energy, metabolism of lipoproteins, synthesis of phospholipids and sphingolipids for the assembly of cellular membranes and they regulate the activity of certain membrane proteins by covalent binding [2] The PUFA have other biological properties that can be resumed as follows:

- At the membrane level, they have a structural effect since some of them are fundamental constituents of membrane phospholipids (linoleic acid, arachidonic acid and DHA) (Tab. I). They modulate the activity of enzymes, carriers and receptors of biological membranes directly or indirectly by determining their physicochemical properties.

- Certain PUFA with 20 carbon atoms are precursors for the synthesis of eicosanoids (Fig. 2). These oxygenated molecules act as a messenger on the cytosolic and intercellular level and regroup the prostaglandins, prostacyclins, thromboxanes, and leukotrienes. They regulate diverse functions such as reproduction, cardiac physiology, blood clotting, inflammation, the function of endocrine and exocrine glands, ... The nature of the dietary precursors is an element of crucial importance that needs to be considered in nutrition since the molecules that are derived often present antagonistic effects [3]. Thus, the synthesis of thromboxanes and leukotrienes from EPA lead to the inhibition of the process of blood clotting, coagulation and inflammation, by opposing to the effects produced by the eicosanoids synthesised from arachidonic acid.

- Arachidonic and docosahexaenoic acids are also substrates of non-enzymatic pathways of peroxidation, leading to the formation of specific endoperoxide molecules named respectively $\mathrm{F}(2$ )-isoprostanes (or $\mathrm{F}(2)$-like compounds) and neuroprostanes [4]. The physiological roles of these molecules are being unfolded and concern notably the functioning of platelets and blood vessels 
Table I. Polyunsaturated fatty acid (PUFA) of physiological and nutritional importance in Humans.

\begin{tabular}{|c|c|c|}
\hline Individual PUFA & $\begin{array}{l}\text { Simplified } \\
\text { formula* }\end{array}$ & Major physiological and/or nutritional roles \\
\hline \multicolumn{3}{|r|}{ n-6 PUFA family (or $\omega 6$ ) } \\
\hline *Linoleic acid (LA) & $18: 2 n-6$ & $\begin{array}{l}\text { Structural role as a major constituent of membrane } \\
\text { phospholipids. The essentiel precursor of n- } 6 \text { PUFA }\end{array}$ \\
\hline $\begin{array}{l}* \gamma \text {-Linolenic acid } \\
(\text { GLA) }\end{array}$ & $18: 3 n-6$ & $\begin{array}{l}\text { Anti-inflammatory effect by inducing the synthesis } \\
\text { and accumulation of } 20: 3 n-6\end{array}$ \\
\hline $\begin{array}{l}* \text { Dihomo- } \gamma \text {-linole- } \\
\text { nic acid (DGLA) }\end{array}$ & $20: 3 n-6$ & Precursor of the series 1 eicosanoids \\
\hline $\begin{array}{l}\text { *Arachidonic acid } \\
\text { (AA) }\end{array}$ & $20: 4 n-6$ & $\begin{array}{l}\text { Structural role as a major constituent of the membrane } \\
\text { phospholipids. Precursor of series } 2 \text { eicosanoids (prostaglandins, } \\
\text { prostacyclins and thromboxanes) and } 4 \text { (leukotrienes) regulating } \\
\text { the platelet aggregation, vasoconstriction and inflammatory } \\
\text { processes. Regulates the expression of a certain number of genes } \\
\text { implicated in the lipid metabolism and in the differentiation } \\
\text { phenomena (adipocyte) }\end{array}$ \\
\hline *Adrenic acid & $22: 4 n-6$ & Constituent of the cerebral membranes \\
\hline $\begin{array}{l}\text { *Docosapentaenoic } \\
\text { acid (n-6 DPA) }\end{array}$ & $22: 5 n-6$ & $\begin{array}{l}\text { Incorporated in the biological membranes in the position of } \\
22: 6 n-3 \text { when n-3 PUFA food deficiency }\end{array}$ \\
\hline
\end{tabular}

n-3 PUFA family (or $\omega 3$ )

* $\alpha$-Linolenic acid

(LNA)

*Stearidonic acid

*Eicosapentaenoic acid (EPA)

*Docosapentaenoic acid (n-3 DPA)

*Docosahexaenoic acid (DHA)
18: $3 n-3$

$20: 5 n-3$

$22: 6 n-3$
The essential precursor of n-3 family PUFA. Antiatherogenic effect

Precursor of series 3 eicosanoids (prostaglandins, prostacyclins and thromboxanes) and 5 (leukotrienes) whose effects are opposite to those of arachidonic acid (antiatherogenic and anti-inflammatory effects) Also produces a hypotriglyceridaemia effect (represses the expression of genes responsible for the hepatic metabolism of lipids)

\footnotetext{
Structural role as the major constituent of lipids in the central nervous system-Participates in the control of a large number of physiological mechanisms in the tissues (ion channels, monoaminergic neurotransmission, energy metabolism, differentiation, apoptosis, ...)
}

* The nomenclature of physiologists successively indicates the number of carbon atoms, the number of
double bonds and the position of the first unsaturation by counting from the methyl end of the molecule. 


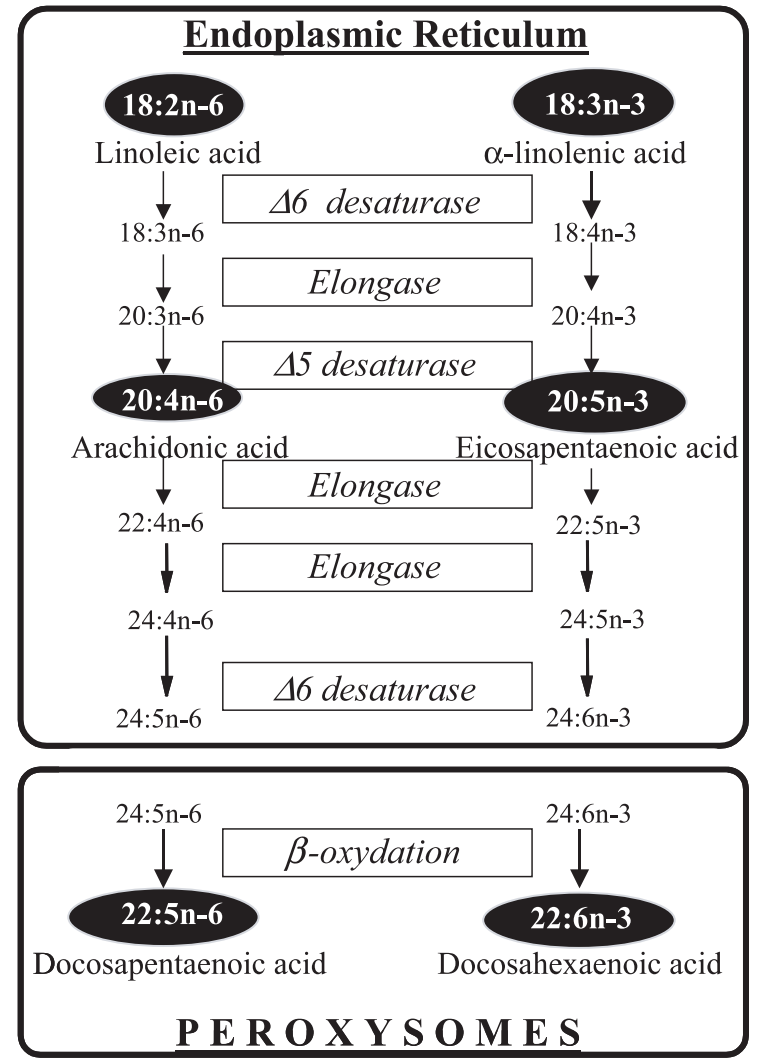

Figure 1. Fatty acid metabolism of essential fatty acids of the $n-6$ and $n-3$ series via the elongationdesaturation pathway. (vasoconstriction, proliferation of smooth muscle cells, monocyte adhesion), ... [5]. - At the level of cell nuclei, especially in adipose, hepatic and muscular tissues, the PUFA regulate the expression of genes implicated in their transport and metabolism. By the intermediary of transcription factors of the superfamily of steroid nuclear receptors [6], the PUFA can stimulate the transcription of enzymes of mitochondrial and peroxysomal $\beta$-oxidation, and repress the transcription of lipogenic enzymes [7]. The pathway of PUFA nuclear receptors is also implicated in the regulation of the transcription of lipoprotein lipase and apolipoproteins of HDL and VLDL.

\section{IMPLICATIONS OF N-3 PUFA IN CARDIOVASCULAR AND INFLAMMATORY PATHOLOGIES, DIABETES AND OBESITY, CANCER AND NEUROPSYCHIATRIC DISEASES}

The particular interest of n-3 PUFA in human nutrition appeared approximately 30 years ago based on epidemiological observations of a comparison between Greenlanders and Danish Eskimos. These observations showed a lower prevalence of cardiovascular and inflammatory diseases in Eskimos that exclusively consume marine animal fats, 

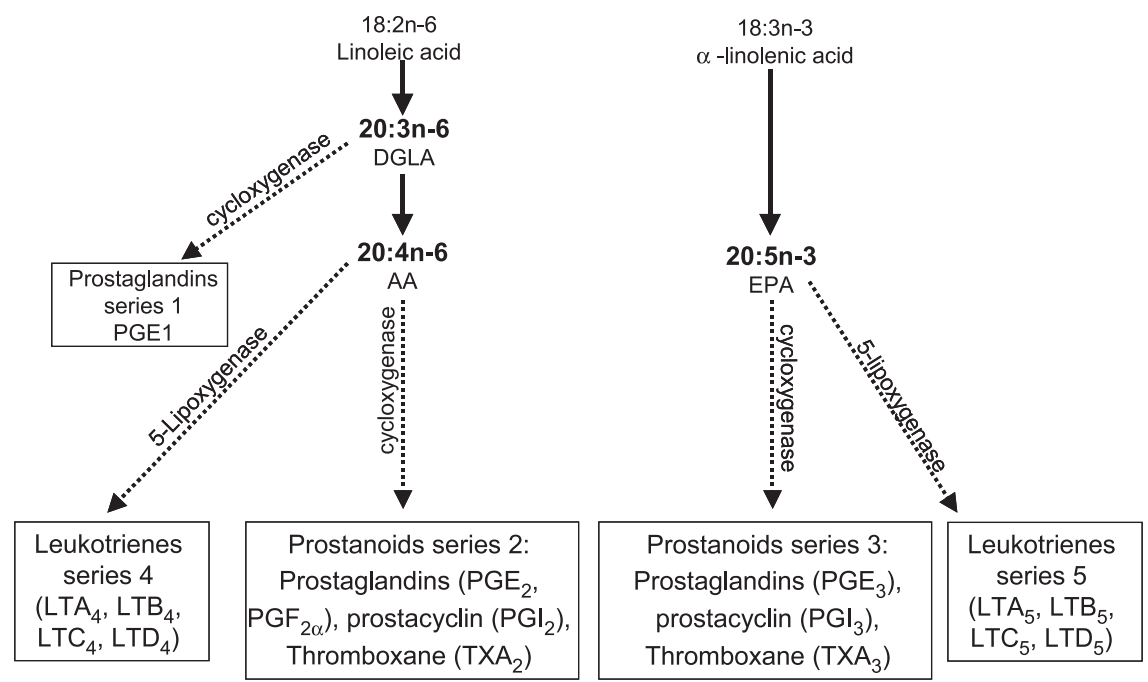

Figure 2. Eicosanoids derived from oxidative metabolism of C20 n-6 and n-3 PUFA by the cyclooxygenase and 5-lipoxygenase pathways.

rich in long-chain $\mathrm{n}-3$ fatty acids [8]. Since 1980 , the acquisition of new scientific knowledge has allowed to show that this family of fatty acids could play a preventive and curative role in cardiovascular pathologies, hypertension, certain inflammatory and autoimmune diseases, cancer, diabetes, and obesity [3, 9]. Recently, scientists have become interested in psychiatric pathologies such as schizophrenia and depression $[10,11]$. Thus, the n-3 PUFA, and notably their long-chain derivatives contained in products issued from the ocean (EPA and DHA), probably would have beneficial properties notably via their anti-inflammatory effects, by stimulating the synthesis of less active derivatives at the inflammatory level and by repressing those of the most active derivatives. These derivatives are mainly eicosanoids issued from a balance of eicosapentaenoic acid/arachidonic acid in favour of eicosapentaenoic acid, but also implicating proinflammatory cytokines whose synthesis is repressed (interleukin-1, IL-1; interleukin-6, IL-6; tumour necrosis factor, TNF $\alpha$ ) [3].

Concerning cardiovascular diseases, the beneficial effects of n-3 PUFA could involve other pathways: the modification of the metabolism of lipoproteins (a hypotriglyceridaemia effect by suppressing the expression of genes in the de novo lipogenesis pathway and by activating those of genes of the $\beta$-oxidation pathway of fatty acids), haemostatic functions, the interaction between platelets and the vascular endothelium, the functioning of the cardiac muscle (against arrhythmia), the adhesion of the leucocytes to the vascular endothelium, ... [12]. In the review that follows, the Drs De Lorgeril and Salen report that the latest studies in secondary prevention do not confirm all the beneficial properties of long-chain n-3 PUFA described previously (notably for the circulating lipids and the haemostatic parameters), and that $\alpha$-linolenic acid (ALA) could be a nutrient that could help control function of cardiac muscle (anti-arrhythmic effect). 
The beneficial properties exercised by the long-chain n-3 PUFA on cardiovascular functions have inspired interest for the treatment of patients with diabetes (types 1 and 2) that present similar hypertriglyceridaemia. This affection is associated with a dysfunctioning of $\Delta 6$ desaturase [1], suggesting that the defect of the biosynthesis of long-chain derivatives could be corrected by a correct nutritional intake of PUFA which has been desaturated at the $\Delta 6$ position. Clinical studies show that a daily intake of the order of one gram of EPA and DHA can limit the cardiovascular complications of disease (circulating triglycerides, platelet aggregation, hypertension). It has been shown that a relationship exists between the consumption of fats and hyperinsulinemia (type 2 diabetes) and that, in animal studies, an intake of n-3 PUFA decreases the insulin resistance phenomenon by modulating several parameters of the processes of insulin signalling. However, it seems that such effects are not observed in man (see the review article [13]).

Type 2 diabetes is closely related to obesity since it is often observed in adults presenting a metabolic syndrome (excess of weight and non insulin-dependent diabete). During development and during the adult life, an increase in adipose mass is generally associated with a diet rich in lipids. Recent experimental data suggest that a high intake of n-6 PUFA to the detriment of n-3 PUFA could favour adipogenesis, in vitro as well as in vivo during the period of perinatal development (gestation-lactation) by activating the process of adipocyte differenciation via specific peroxisome proliferatoractivated receptors (PPARs) and their endoperoxide derivatives (prostacyclins) [14] The increase in the prevalence of obesity observed in all countries in the world over the last thirty years, and notably in youth, with, at the same time, an increase in the consumption of n-6 PUFA without a notable change in the amounts of total fatty acids ingested, supports the hypothesis that PUFA intake could be a nutritional factor that should be considered in the battle against this pathology [9].

The $n-3$ PUFA, on the contrary to $n-6$ PUFA, present marked immunomodulating and anti-inflammatory properties, with the long-chain derivatives such as EPA and DHA having more noticeable effects than linolenic acid. These effects have been shown in a multitude of epidemiological and clinical studies. Generally, they are directly issued from the effects of EPA that are in competition with those of arachidonic acid as the substrate of the cyclooxygenase and 5-lipoxygenase pathways, generating anti-inflammatory derivatives (Fig. 2) [3]. These PUFA also decrease the expression of cyclooxygenase $2(\mathrm{COX}-2)$ which limits the production of endoperoxide derivatives. They specifically inhibit the expression and liberation of cytokines such as IL- 1 and IL-6 and TNF, but also the synthesis of molecules implicated in endothelial adherence such as the activation and the proliferation of $\mathrm{T}$ lymphocytes $[1,3]$. Altogether, these effects could explain the beneficial properties that this family of fatty acids has on certain inflammatory pathologies (rheumatoid arthritis, psoriasis, asthma, and inflammatory bowel disease, Crohn disease and ulcerative colitis) [3].

The intake of food lipids is one of the factors that seems to play an important role as an adjuvant in therapeutic treatments of cancer [1]. In the animal models for experimental carcinogenesis, n-6 PUFA favour tumour growth, on the contrary to longchain n-3 PUFA that inhibit it. The mechanisms proposed are the effects of a competition that exists between n-3 PUFA and arachidonic acid for the synthesis of eicosanoids, and the particularity of n-3 PUFA to be more cytotoxic for tumoral cells by radicalar oxidation [1]. Recently, it has been shown that dietary DHA increased mammary tumor sensitivity to radiation in a rat model of chemically induced mammary tumors [15]. However, even though some prospective case-control studies confirm these animal data and underline the fact that 
the ratio between n-6 PUFA and n-3 PUFA is negatively associated with the incidence of breast cancer [16, 17], recent metaanalyses are not conclusive concerning a protecting effect of food lipids for this type of cancer. In addition, they underline the interest in developing new prospective studies on a large scale and in including a nutritional intervention with genetic/genomic data $[18,19]$.

Finally, the n-3 PUFA and notably docosahexaenoic acid (22:6n-3, DHA) are nutrients essential for the normal development of the central nervous system (brain, retina). Indeed, due to its exceptionally high concentration in the excitable membranes of the brain and retina, DHA plays a fundamental role in the physiology of nervous tissue [20]. Under the influence of a chronic experimental nutritional deficiency of $n-3$ PUFA (that is maintained during the whole period of gestation and lactation), the decrease in the amount of DHA in the membrane is accompanied by a decrease in the learning capacities and visual discrimination in rodents and monkeys (memory, attention, motivation). Several cases of nutritional deficiencies have been reported in man, notably in new-born infants that present a delay in the development of their visual acuity $[21,22]$. A neurochemical support has been advanced, allowing to establish a relationship between the decrease in cerebral concentrations of DHA and behavioural modifications observed with animal models [23-25]. This concerns the monoaminergic and cholinergic neurotransmissions whose pathways would be altered by a deficiency, probably by modifying the processes of storage and synaptic release of these neurotransmitters. This type of a relationship could also be implicated in the appearance of neurological troubles associated with a pathology (hyperactivity in children, schizophrenia, depression, ....) [26, 27]. In schizophrenic patients, abnormalities of the metabolism of PUFA and membrane phospholipids have been identified mainly as an increased catabolism and abnormal activation of phospholipase $A_{2}$, possibly implicating a hyperfunctioning of the signalling pathway by arachidonic acid and its endoper- oxide derivatives (prostaglandins) [3, 28]. The consumption of long-chain n-3 PUFA at about one g.day ${ }^{-1}$ could improve the symptoms of this neuropathology and would be imputed to a specific effect of EPA [29]. For depression, human studies describing the effects of n-3 PUFA are only at the beginning, but the first clinical experiments show a promising potential effect of the consumption of these fatty acids as an adjuvant to antidepressants, or as an option for minor depressions [11, 30]. The mechanisms of action of n-3 PUFA in this pathology are not exactly known and should concern the inhibition of the inflammatory state. Finally, the intake of long-chain n-3 PUFA could also be beneficial towards the incidence of neuropathologies associated with ageing as is suggested in recent epidemiological and prospective studies (Alzheimer disease, senile dementia) [31, 32], leaving the door open to the possible use of dietary long-chain n-3 PUFA.

\section{CONCLUSIONS}

The n-3 PUFA intake from food, whether it is ingested as the essential precursor as $\alpha$-linolenic acid or its long-chain derivatives (EPA and DHA), is important for the neurosensory development of the newborn. It can also play a role in the frequency of the occurrence or at least in the intensity of the symptoms of certain pathological disorders such as cardiovascular diseases, cancer, diabetes, obesity, and inflammatory and central nervous system pathologies. The absence of a diversification of our food intake is probably responsible for the progressive increase of the disequilibrium in the intake of n-6 and n-3 PUFA. For many of us, our food intake is too rich in n- 6 and relatively poor in n-3 (precursor and long-chain derivatives). This disequilibrium is detrimental to the synthesis of long-chain n-3 PUFA and to their incorporation in tissues $[9,33]$ and thus contributing to the emergence of these pathologies. The large variability of the amounts and compositions of fatty acids 
in food lipids, whether of vegetable or animal origin, underline the importance of food diversification in order to avoid an excess or disequilibrium of fatty acid intake. Moreover, the consumption of fish and ocean food is recommended due to the interest of long-chain n-3 PUFA (EPA + DHA) in the prevention of several diseases.

\section{REFERENCES}

[1] Durand G, Guesnet Ph, Chalon S, Alessandri JM, Rizkalla S, Lebranchu Y. Importance nutritionnelle des acides gras polyinsaturés. In: Aliments Fonctionnels, Marcel Roberfroid (Ed), Éditions Tec \& Doc-Lavoisier, Paris, 2002, p 193-219.

[2] Rioux V, Daval S, Guillou H, Jan S, Legrand $\mathrm{P}$. Although it is rapidly metabolized in cultured rat hepatocytes, lauric acid is used for protein acylation. Reprod Nutr Dev 2003, 43: 419-430.

[3] Simopoulos AP. Omega-3 fatty acids in inflammation and autoimmune diseases. J Am Coll Nutr 2002, 21: 495-505.

[4] Roberts LJ, Fessel JP. The biochemistry of the isoprostane, neuroprostane, and isofuran pathways of lipid peroxidation. Chem Phys Lipids 2004, 128: 173-186.

[5] Cracowski JL. Isoprostanes: an emerging role in vascular physiology and disease? Chem Phys Lipids 2004, 128: 75-83.

[6] Khan SA, Vanden Heuvel JP. Role of nuclear receptors in the regulation of gene expression by dietary fatty acids. J Nutr Biochem 2003, 14: 554-567.

[7] Clarke S. Polyunsaturated Fatty Acid Regulation of Gene Transcription: A Molecular Mechanism to Improve the Metabolic Syndrome. J Nutr 2001, 131: 1129-1132.

[8] Kromann N, Green A. Epidemiological studies in the Upernavik district, Greenland. Incidence of some chronic diseases 1950-1974. Acta Med Scand 1980, 208: 401-406.

[9] Ailhaud G, Guesnet P. Fatty acid composition of fats is an early determinant of childhood obesity: a short review and an opinion. Obes Rev 2004, 5: 21-26.

[10] Emsley R, Oosthuizen P, van Rensburg SJ. Clinical potential of omega- 3 fatty acids in the treatment of schizophrenia. CNS Drugs 2003, 17: 1081-1091.
[11] Astorg P. Acides gras polyinsaturés n-3 et dépression : des espoirs pour la prévention et la thérapeutique. NAFAS 2003, 1: 3-11.

[12] Abeywardena MY, Head RJ. Long chain n-3 polyunsaturated fatty acids and blood vessel function. Cardiovasc Res 2001, 52: 361-371.

[13] Delarue J, Le Foll C, Corporeau C, Lucas D. n-3 long chain polyunsaturated fatty acids: a nutritional tool to prevent insulin resistance associated to type 2 diabetes and obesity? Reprod Nutr Dev 2004, 44: 287-257.

[14] Massiera F, Saint-Marc P, Seydoux J, Murata T, Kobayashi T, Narumiya S, Guesnet P, Amri EZ, Negrel R, Ailhaud G. Arachidonic acid and prostacyclin signaling promote adipose tissue development: a human health concern? J Lipid Res 2003, 44: 271-279.

[15] Colas S, Paon L, Denis F, Prat M, Louisot P, Hoinard C, Le Floch O, Ogilvie G, Bougnoux $P$. Enhanced radiosensitivity of rat autochthonous mammary tumors by dietary docosahexaenoic acid. Int J Cancer 2004, 109: 449_ 454.

[16] Maillard V, Bougnoux P, Ferrari P, Jourdan ML, Pinault M, Lavillonniere F, Body G, Le Floch O, Chajes V. n-3 and n-6 fatty acids in breast adipose tissue and relative risk of breast cancer in a case-control study in Tours, France. Int J Cancer 2002, 98: 78-83.

[17] Bougnoux P, Maillard V, Ferrari P, Jourdan ML, Chajes V. n-3 fatty acids and breast cancer. IARC Sci Publ 2002, 156: 337-341.

[18] Prentice RL. Future possibilities in the prevention of breast cancer. Fat and fiber and breast cancer research. Breast Cancer Res 2000, 2: 268-276.

[19] Berrino F, Krogh V, Riboli E. Epidemiology studies on diet and cancer. Tumori 2003, 89: 581-585.

[20] Haag M. Essential fatty acids and the brain. Can J Psychiatry 2003, 48: 195-203.

[21] Guesnet P, Alessandri JM. Acides gras polyinsaturés du lait et développement du système nerveux central du nouveau-né. Cah Nutr Diet 1995, 30: 109-116.

[22] Innis SM. Perinatal biochemistry and physiology of long-chain polyunsaturated fatty acids. J Pediatr 2003, 143: S1-S8.

[23] Delion S, Chalon S, Guilloteau D, Besnard JC, Durand G. Alpha-Linolenic acid dietary deficiency alters age-related changes of dopaminergic and serotoninergic neurotransmission in the rat frontal cortex. J Neurochem 1996, 66: 1582-1591. 
[24] Zimmer L, Vancassel S, Cantagrel S, Breton P, Delamanche S, Guilloteau D, Durand G, Chalon S. The dopamine mesocorticolimbic pathway is affected by deficiency in n-3 polyunsaturated fatty acids. Am J Clin Nutr 2002, 75: 662-667.

[25] Aid S, Vancassel S, Poumes-Ballihaut C, Chalon S, Guesnet P, Lavialle M. Effect of a diet-induced n-3 PUFA depletion on cholinergic parameters in the rat hippocampus. J Lipid Res 2003, 44: 1545-1551.

[26] Chalon S, Vancassel S, Zimmer L, Guilloteau D, Durand G. Polyunsaturated fatty acids and cerebral function: focus on monoaminergic neurotransmission. Lipids 2001 36: 937-944.

[27] Vancassel S. Oméga 3 et neurotransmission cérébrale. OCL 2004, 11: 58-65.

[28] Skosnik PD, Yao JK. From membrane phospholipid defects to altered neurotransmission: is arachidonic acid a nexus in the pathophysiology of schizophrenia? Prostaglandins Leukot Essent Fat Acids 2003, 69: 367-384.
[29] Emsley R, Oosthuizen P, Van Rensburg SJ. Clinical potential of omega-3 fatty acids in the treatment of schizophrenia. CNS Drugs 2003, 17: 1081-1091.

[30] Logan AC. Neurobehavioral aspects of omega-3 fatty acids: possible mechanisms and therapeutic value in major depression. Altern Med Rev 2003, 8: 410-425.

[31] Morris MC, Evans DA, Bienias JL, Tangney CC, Bennett DA, Wilson RS, Aggarwal N, Schneider J. Consumption of fish and n-3 fatty acids and risk of incident Alzheimer disease. Arch Neurol 2003, 60: 940-946.

[32] Kalmijn S. Fatty acid intake and the risk of dementia and cognitive decline: a review of clinical and epidemiological studies. J Nutr Health Aging 2000, 4: 202-207.

[33] Guesnet P, Couet C, Alessandri JM, Antoine JM, Durand G. Variabilité de la teneur en acide linoléique (18:2n-6) et du rapport 18:2n6/18:3n-3 des lipides dans le lait de femme en France. Ann Pédiatr 1995, 42: 282-288. 